\title{
Pest insect olfaction in an insecticide-contaminated environment: info-disruption or hormesis effect
}

\author{
Hélène Tricoire-Leignel, Steeve Hervé Thany, Christophe Gadenne and Sylvia Anton* \\ Laboratoire Récepteurs et Canaux loniques Membranaires, UPRES-EA 2647 USC INRA 1330, Faculté des Sciences, Université d'Angers, Angers, France
}

Edited by:

Monique Gauthier, University Paul

Sabatier (Toulouse 3), France

\section{Reviewed by:}

Jesper Givskov Sørensen, Aarhus

University, Denmark

Sabine Kreissl, University of

Konstanz, Germany

*Correspondence:

Sylvia Anton, Laboratoire Récepteurs et Canaux loniques Membranaires, UPRES-EA 2647 USC INRA 1330, Université d'Angers, 2 Boulevard Lavoisier, 49045 Angers, France. e-mail:sylvia.anton@angers.inra.fr
Most animals, including pest insects, live in an "odor world" and depend strongly on chemical stimuli to get information on their biotic and abiotic environment. Although integrated pest management strategies including the use of insect growth regulators (IGRs) are increasingly developed, most insect pest treatments rely on neurotoxic chemicals. These molecules are known to disrupt synaptic transmission, affecting therefore sensory systems. The wide-spread use of neurotoxic insecticides and the growing use of IGRs result in residual accumulation of low concentrations in the environment. These insecticide residues could act as an "info-disruptor" by modifying the chemical communication system, and therefore decrease chances of reproduction in target insects. However, residues can also induce a non-expected hormesis effect by enhancing reproduction abilities. Low insecticide doses might thus induce adaptive processes in the olfactory pathway of target insects, favoring the development of resistance. The effect of sublethal doses of insecticides has mainly been studied in beneficial insects such as honeybees. We review here what is known on the effects of sublethal doses of insecticides on the olfactory system of insect pests.

Keywords: olfaction, pest management, insecticides, sex pheromone, plasticity

\section{INTRODUCTION}

Insects cause economically important damage on crop yield by direct feeding damage, defoliation, and transmission of plant viruses. Although biological control methods have been developed for some insect species (Díaz et al., 2012), chemical insecticides, based on varying modes of action, are still used in large quantities to limit insect damage in agriculture (Casida, 2009). Insecticides per se or as its bioactivated form should interact with the target initiating a series of events which could be considered as "negative" because they cause behavioral/physiological damages or insect death (Buckingham et al., 2005; El Hassani et al., 2005; Davies et al., 2007; Tan et al., 2007; Casida, 2009; Benzidane et al., 2010; Oliveira et al., 2011). Many insecticides disrupt neurotransmission and thus alter, e.g., locomotor activity, sensory systems, and cognitive abilities (El Hassani et al., 2008; Benzidane et al., 2010). Growth regulators on the other hand influence endocrine control of the insect's physiology and disrupt development (Casida, 2009; Merzendorfer et al., 2012).

The wide use of insecticides as systemic formulation to whole fields or as a seed treatment over long periods of time causes residues at low doses in the environment. They can create selection pressure so that different pest insect species have developed a strong resistance to virtually all insecticides used for their control (Mota-Sanchez et al., 2006; Ling et al., 2011). Generally sublethal insecticide residues have been shown to cause multiple effects on development and reproduction of both beneficial and pest insect species. In particular, reproduction involves a complex series of behavioral and physiological events, which are precisely coordinated by the insect's nervous and hormonal systems. Sublethal doses of insecticides can upset this coordination and thereby result in diminished reproductive success. Most often only the end result of sublethal poisoning, a decrease in production of viable offspring, is documented in the literature. More recently, however, there is increasing interest in effects of sublethal doses of insecticides on sensory and nervous systems in the context of the decline of populations of both the domestic honeybee and wild bees (reviewed in Desneux et al., 2007). As the most commonly used insecticides are blocking neurotransmission, effects of sublethal doses on sensory systems such as olfaction are likely to occur. In honeybees sublethal doses of insecticides have been shown to interfere with olfactory-guided behavior and learning and memory of olfactory cues, as recently reviewed by Desneux et al. (2007). We will review here the much more scarce literature on effects of sublethal doses of different types of insecticides on the olfactory system and olfactory-guided behavior in agricultural pest insects (Table 1). This is an important issue, because such effects might impact on integrated pest management strategies. We discuss the impact of these effects on adaptive mechanisms and provide perspectives for future research in this field.

\section{OLFACTION, A CRUCIAL SENSE IN AGRICULTURAL PEST INSECTS}

Most agricultural pest insects use olfactory cues to communicate with their mating partners, to localize food sources and oviposition sites. Both environmental odors, such as plant volatiles and different types of pheromones, produced by conspecifics are crucial for optimizing survival and reproduction. Apart from pheromones involved in social communication in honeybees and ants, the most well-described pheromone system is the moth sex pheromone system, where the female produces a species-specific 
Table 1 | List of identified effects of sublethal doses of insecticides on the olfactory system of insect pests.

\begin{tabular}{|c|c|c|c|c|c|}
\hline Type of effect & & Insecticide type & Active compound & Insect species & Reference \\
\hline \multirow[t]{5}{*}{$\begin{array}{l}\text { Negative effect } \\
\text { on behavior }\end{array}$} & \multirow[t]{5}{*}{$\begin{array}{l}\text { Response to sex } \\
\text { pheromone }\end{array}$} & \multirow[t]{2}{*}{$\begin{array}{l}\text { Insect growth } \\
\text { regulator }\end{array}$} & Tebufenozide & $\begin{array}{l}\text { Choristoneura } \\
\text { fumiferana - C. rosaceana }\end{array}$ & Dallaire et al. (2004) \\
\hline & & & Methoxyfenozide & Cydia pomonella & $\begin{array}{l}\text { Barrett (2010); Hoelscher and Bar- } \\
\text { rett (2003) }\end{array}$ \\
\hline & & $\begin{array}{l}\text { Cholinesterase } \\
\text { inhibitor }\end{array}$ & Carbaryl & G. molesta & Linn and Roelofs (1984) \\
\hline & & Organophosphate & Malathion & Ostrinia furnacalis & Zhou et al. (2005) \\
\hline & & Pyrethroids & Permethrin & Pectinophora gossypiella & $\begin{array}{l}\text { Haynes and Baker (1985); Haynes } \\
\text { et al. (1986); Moore (1988) }\end{array}$ \\
\hline $\begin{array}{l}\text { Positive effect } \\
\text { on behavior }\end{array}$ & $\begin{array}{l}\text { Response to sex } \\
\text { pheromone }\end{array}$ & Formamidine & Chlordimeform & $\begin{array}{l}\text { G. molesta } \\
\text { T. ni }\end{array}$ & $\begin{array}{l}\text { Linn and Roelofs (1984) } \\
\text { Linn and Roelofs (1985) }\end{array}$ \\
\hline Negative effect & EAG & Organophosphate & Malathion & O. furnacalis & Zhou et al. (2005) \\
\hline \multirow[t]{2}{*}{ on periphery } & EAG (not significant) & Oxadiazine & Indoxacarb & Plutella xylostella & Wang et al. (2011) \\
\hline & $\begin{array}{l}\text { Olfactory receptor } \\
\text { neuron response }\end{array}$ & Pyrethroid & Deltamethrin & $\begin{array}{l}\text { Mamestra brassicae - M. } \\
\text { suasa }\end{array}$ & Lucas and Renou (1992) \\
\hline $\begin{array}{l}\text { Negative effect } \\
\text { on central level }\end{array}$ & $\begin{array}{l}\text { Development of AL } \\
\text { glomeruli }\end{array}$ & Pyrethroid & Fenvalerate & Manduca sexta & Wegerhoff et al. (2001) \\
\hline
\end{tabular}

blend of molecules, which are detected over a large distance by a highly sensitive and specific olfactory system in the male (e.g., Hildebrand, 1995; Sakurai et al., 2011). Plant-related odors, are on the other hand detected by a slightly less specific, but often still very highly sensitive olfactory system in both males and female insects (Christensen and Hildebrand, 2002). Both types of generally hydrophobic odor molecules are transported by odorant-binding proteins through the sensillum lymph, surrounding the dendrites of olfactory receptor neurons (ORNs; Jacquin-Joly and Lucas, 2005) situated in pored cuticular sensilla on the antennae and mouthparts (Keil, 1999). At the membrane, odor molecules bind to specific receptor molecules and elicit a transduction cascade leading to the emission of action potentials (reviewed in Jacquin-Joly and Lucas, 2005; Stengl, 2010). Whereas most ORNs have broadly tuned molecular response profiles to ensure detection of the vast array of odorant molecules, pheromone-detecting ORNs respond often very specifically to individual pheromone components. Action potentials are then transmitted to the primary olfactory center, the antennal lobe (AL) via ORN axons (Anton and Homberg, 1999). The activated axons of the ORNs elicit odor-specific spatio-temporal activity patterns within globular neuropil, the glomeruli, and make synaptic contact with two morphologically distinct types of AL neurons, local interneurons (LNs), and projection neurons (PNs; Anton and Homberg, 1999; Galizia and Rössler, 2010). The network of LNs is restricted to the AL and represents a first relay station processing incoming information, while PNs transmit information to higher centers of the brain, the mushroom bodies (MBs) and the lateral protocerebrum (Anton and Homberg, 1999; Galizia and Rössler, 2010). The MBs are a second-order olfactory neuropil closely associated with the chemosensory system of the AL and are involved in learning and memory, multimodal integration, and spatial orientation (Menzel and Müller, 1996; Heisenberg, 2003; Busto et al., 2010). Different areas of the protocerebrum are then connected via descending pathways to thoracic ganglia, allowing adapted motor output (De Belle and Kanzaki, 1999).

Although insects have for long been believed to have hardwired nervous systems, a high degree of plasticity is known for a long time in honeybees, where the olfactory system is modulated as a function of, e.g., experience and age (e.g., Faber et al., 1999; Brown et al., 2004; Wang et al., 2005). More recently, the behavioral and central nervous responses of male moths to the female-emitted sex pheromone have also been shown to be highly plastic. Sensory experience and the physiological state, regulated by hormones and neuromodulators, modify pheromone responses strongly (Gadenne et al., 1993, 2001; Anton and Gadenne, 1999; Anderson et al., 2003, 2007; Anton et al., 2007, 2011).

\section{EFFECTS OF SUBLETHAL DOSES OF INSECTICIDE ON OLFACTION "NEGATIVE" EFFECTS ON BEHAVIOR}

Every class of insecticide, including growth regulators, has been shown to decrease the production of offspring (review in Haynes, 
1988). A reduction in offspring could indicate one or more of many adverse effects, including effects on mate-locating, courtship, oviposition, and associated physiological events such as spermatogenesis, sperm motility, oogenesis, ovulation, and egg fertilization (e.g., Bao et al., 2009; Ling et al., 2011; Wijayaratne et al., 2012). We summarize here mainly the effects of sublethal doses of insecticides on the odor-guided behavior of agricultural pest insects (Table 1) and refer only occasionally to beneficial insects such as honeybees, because this literature has been extensively reviewed recently (Desneux et al., 2007). Most insects use olfactory cues to find their sexual partner and to localize host plants and food sources. In these cases, pollution with low doses of chemicals acts as info-disruptor for chemical communication causing maladaptive responses in both the signaller and the receiver (Lürling and Scheffer, 2007).

In different moth species, response to sex pheromone is altered when males are treated with sublethal doses of insecticides (review in Haynes, 1988). Field treatments with the ecdysteroid agonists tebufenozide and methoxyfenozide decrease male responses to pheromone in the tortricid moths Choristoneura fumiferana, C. rosaceana, Argyrotaenia velutinana, Cydia pomonella, and Grapholita molesta (Hoelscher and Barrett, 2003; Dallaire et al., 2004; Reinke and Barrett, 2007; Barrett, 2008). Interestingly, methoxyfenozide also disrupted responses of codling moth males to pear ester, a highly attractive plant odor (Barrett, 2010).

The cholinesterase inhibitor carbaryl disrupted zigzagging upwind flight, and the organochloride chlordimeform interfered with all sequences of flight and courtship display in Grapholita molesta (Linn and Roelofs, 1984). In the corn borer Ostrinia furnacalis, treatments with the organophosphate malathion decrease the ability of males to respond to the female-produced sex pheromone (Zhou et al., 2005). The pyrethroids permethrin, deltamethrin, and cypermethrin, sodium channel activators, disrupt male attraction to sex pheromone in the pink bollworm, Pectinophora gossypiella, the corn borer O. furnacalis, and the noctuid Trichoplusia ni (Haynes and Baker, 1985; Haynes et al., 1986; Moore, 1988; Clark and Haynes, 1992; Wei and Du, 2004). The ryanodine receptor agonist chlorantraniliprole was recently shown to disrupt male attraction to pheromone in C. pomonella (Knight and Flexner, 2007). Although neonicotinoid insecticides have been shown to alter the larval development and reproductive abilities in aphids and moths (Cutler et al., 2009; Kullik et al., 2011; Shi et al., 2011), no study has shown any effects on the behavioral response to sex pheromone or any other odor so far. In the honeybee, effects of sublethal doses of neonicotinoids have been well studied (review in Desneux et al., 2007). In particular, cognitive processes, such as learning and memory, and also vital behaviors such as foraging have been shown to be impaired following sublethal treatments by neonicotinoids (e.g., Yang et al., 2008; Aliouane et al., 2009; Decourtye et al., 2011). In another hymenopteran, Anagrus nilaparvatae, an egg parasitoid of a rice planthopper, orientation behavior was disrupted after treatment with sublethal doses of imidacloprid (Liu et al., 2010). In bumblebees, foraging behavior was impaired under treatment with different neonicotinoid insecticides (Mommaerts et al., 2010).

\section{“NEGATIVE" EFFECTS ON THE OLFACTORY SYSTEM}

Few studies have shown that non-lethal doses of insecticides may affect the peripheral detection of sex pheromone (Table 1). In the corn borer O. furnacalis, electroantennogram (EAG) responses to pheromone were disrupted after malathion treatment (Zhou et al., 2005), whereas no effect of the sodium channel blocker indoxacarb on EAG responses was observed in the microlepidopteran Plutella xylostella (Wang et al., 2011). At the sensillar level, deltamethrin disrupted the responses of ORNs to pheromone in males of two Mamestra species (Lucas and Renou, 1992). Recently, two other pyrethroid insecticides (tetramethrin and permethrin) were shown to impair honeybee ORN physiology (Kadala et al., 2011) but how these insecticides disrupt ORN responses remains to be elucidated. Neonicotinoid insecticides were also shown to affect ion channel physiology of cultured central olfactory neurons (of the $\mathrm{AL}$ and the MBs), acting as nicotinic receptor agonists in honeybees, however, without knowing the precise role of the investigated neurons for olfactory processing (Nauen et al., 2001; Deglise et al., 2002; Wüstenberg and Grünewald, 2004; Barbara et al., 2008). Numerous studies have been performed on the effects of neonicotinoid insecticides on olfactory learning and memory in the honeybee, but essentially at the behavioral level (review in Desneux et al., 2007). At sublethal doses, orally applied acetamiprid impaired long-term retention of olfactory cues (El Hassani et al., 2008). Interestingly, contact exposure of honeybees to sublethal doses of thiamethoxam induced either a significant decrease of olfactory memory $24 \mathrm{~h}$ after learning, or a significant impairment of learning performance with no effect on memory (Guez et al., 2003; Aliouane et al., 2009). Differentiating the memory impairment from effects on olfactory detection and processing is now required. One piece of evidence on insecticide effects on the central olfactory system comes from the tobacco hornworm, in which sublethal pyrethroid doses affect the development of olfactory glomeruli in the brain (Wegerhoff et al., 2001; Table 1).

\section{"POSITIVE" EFFECTS ON BEHAVIOR}

In addition to these negative behavioral effects, unexpected positive effects of low doses of insecticides on the physiology and reproduction have been reported. Surprisingly, chlordimeform treatment at very low-dose induced a very high sensitivity to sex pheromone in G. molesta (Linn and Roelofs, 1984) and in T. ni (Linn and Roelofs, 1985; Table 1). These last results show that such factors as potential for recovery, insecticide metabolism, and repeated contact with the substance must be carefully considered when evaluating the potential for use of insecticides at sublethal doses. In this context, the phenomenon of hormesis has been defined as characterized by a low-dose stimulation and a highdose inhibition by a given compound (Calabrese and Baldwin, 2003; Guedes et al., 2010). Stimulatory effects associated with low doses of compounds that are toxic at higher doses, such as pesticides, have been widely reported lately and it is currently becoming recognized as a general toxicological phenomenon (Calabrese and Baldwin, 2003; Calabrese, 2004). Evidence of such a biphasic doseresponse relationship for pesticides is scant among insects and other invertebrates, but recognized as one of the potential causes underlying pest resurgence and secondary pest outbreaks. Interestingly, sublethal doses of neonicotinoid or pyrethroid insecticides 


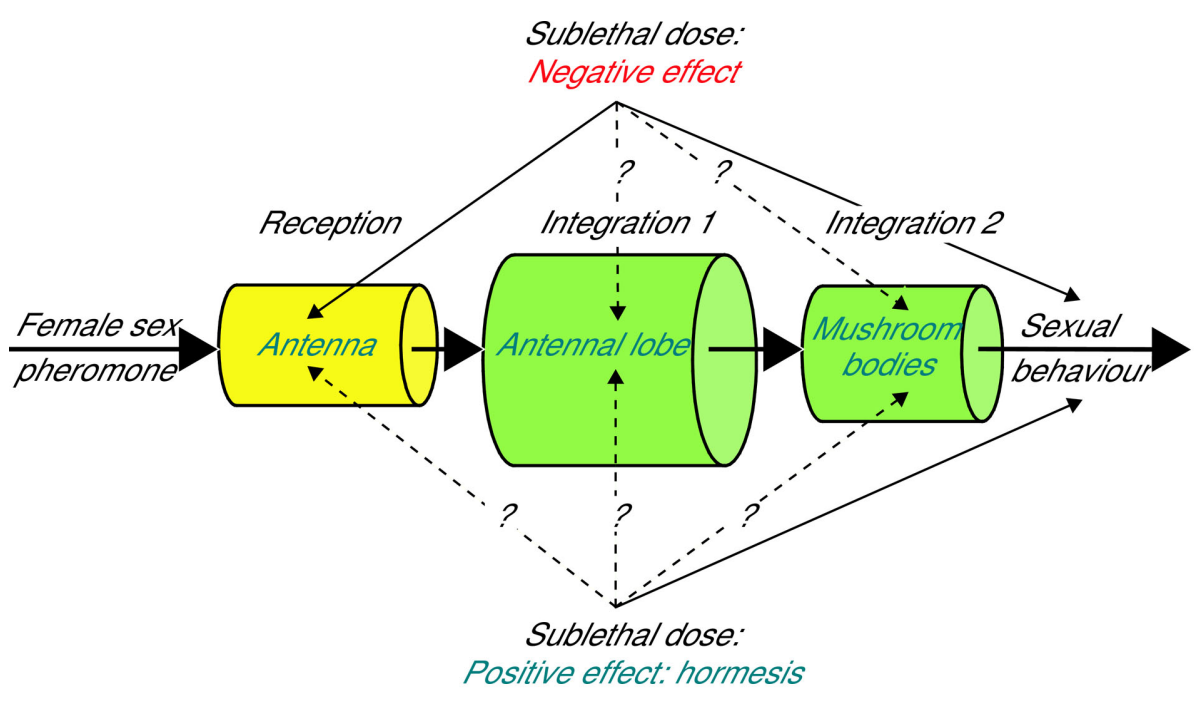

FIGURE 1 | Schematic representation of the observed and suspected effects of sublethal doses of insecticides on the olfactory system of moths.

have been shown to lead to an increase in progeny in various insect species, such as the brown planthopper, aphids and a weevil (Hardin et al., 1995; Morse, 1998; Cohen, 2006; Cutler et al., 2009; Guedes et al., 2010; Ling et al., 2011). If we want to develop efficient integrated pest management over long periods of time, we will have to consider potential "positive" effects of sublethal insecticide doses and its underlying mechanisms. To investigate such mechanisms, we consider olfactory-guided behavior and sensitivity of the olfactory system as an interesting model system to test biphasic dose-response effects and potential hormetic effects of neurotoxic insecticides in pest insects.

\section{CONCLUSION AND FUTURE DIRECTIONS}

In crop protection, pest insect populations are limited through chemical treatments involving either neurotoxic molecules or insect growth regulators (IGRs). In both cases, residues arise in the environment, and the literature reviewed here shows that the effects of such sublethal doses of insecticides are highly dosedependent. Indeed, the toxicological paradox of hormesis was identified in various insect species and is suggested as a possible cause of pest insect resurgence. The mechanisms underlying these dose-dependent effects are, however, largely unknown. The well-described olfactory system of insects, which hosts targets for different neurotoxic molecules, will be very useful to study dose-dependent changes caused by insecticides, because

\section{REFERENCES}

Aliouane, Y., El Hassani, A. K., Gary, V., Armengaud, C., Lambin, M., and Gauthier, M. (2009). Subchronic exposure of honeybees to sublethal doses of pesticides: effects on behavior. Environ. Toxicol. Chem. 28, $113-122$.

Anderson, P., Hansson, B. S., Nilsson, U., Han, Q., Sjöholm, M., Skals, N., and Anton, S. (2007). Increased behavioral and neuronal sensitivity to sex

insects highly rely on their olfactory system and exhibit stereotyped and easy to quantify olfactory-guided behaviors. In moths, which count for many agricultural pest insects, the highly specific and well-described sex pheromone system will provide an excellent model system to investigate mechanisms of low-dose insecticide action (Figure 1). However, effects on orientation toward host plant odors should also be considered, specifically in females, because they could have an important impact on reproductive success. Evidently, understanding hormetic pesticide effects on "beneficial" insects, such as pollinators, might also help in the future to limit their decline. In nature, the presence of insecticides will coincide with other signals emitted by the environment or conspecifics and internal signals such as hormones. The hormone-, neuromodulator-, and experiencecontrolled plasticity of the olfactory system described in moths provides an additional dimension to understand the action of low doses of different insecticides in a physiological and environmental context.

Understanding mechanisms of dose-dependent insecticide action will be crucial in the future if we want to continue to use insecticide treatments in an environmentally acceptable way. It is not enough to follow degradation of insecticides in the biotic and abiotic environment, but we also need to know how different doses of residues affect insect behavior and physiology in addition to reproductive success.

and locusts. Entomol. Exp. Appl. 123, $1-11$.

Anton, S., Evengaard, K., Barrozo, R. B., Anderson, P., and Skals, N. (2011) Brief predator sound exposure elicits behavioral and neuronal long-term sensitization in the olfactory system of an insect. Proc. Natl. Acad. Sci. U.S.A. 108, 3401-3405.

Anton, S., and Gadenne, C. (1999). Effect of juvenile hormone on the central nervous processing of sex pheromone in an insect. Proc. Natl. Acad. Sci. U.S.A. 96, 5764-5767.

Anton, S., and Homberg, U. (1999).

"Antennal lobe structure," in Insect Olfaction, ed. B. S. Hansson (Berlin: Springer), 98-125.

Bao, H., Liu, S., Gu, J., Wang, X., Liang, X., and Liu, Z. (2009). Sublethal effects of four insecticides on the reproduction and wing formation of brown planthopper, Nilaparvata lugens. Pest Manag. Sci. 65, 170-174. 
Barbara, G. S., Grünewald, B., Paute, S., Gauthier, M., and RaymondDelpech, V. (2008). Study of nicotinic acetylcholine receptors on cultured antennal lobe neurones from adult honeybee brains. Invert. Neurosci. 8, 19-29.

Barrett, B. A. (2008). Assessment of methoxyfenozide exposure on the sexual attractiveness and responsiveness of adult codling moth, Cydia pomonella (L.), in small orchard blocks. Pest Manag. Sci. 64, 916-922.

Barrett, B. A. (2010). Exposure to methoxyfenozide-treated surfaces reduces the responsiveness of adult male codling moth (Lepidoptera: Tortricidae) to codlemone and pear ester lures in a wind tunnel. J. Econ. Entomol. 103, 1704-1710.

Benzidane, Y., Touinsi, S., Motte, E., Jadas-Ecart, A., Communal, P.-Y., Leduc, L., and Thany, S. H. (2010). Toxicity of thiamethoxam on cockroach locomotor activity associated to its metabolite clothianidin. Pest Manag. Sci. 66, 1351-1359.

Brown, S. M., Napper, R. M., and Mercer, A. R. (2004). Foraging experience, glomerulus volume, and synapse number: a stereological study of the honey bee antennal lobe. J. Neurophysiol. 60, 40-50.

Buckingham, S. D., Biggin, P. C., Sattelle, B. M., Brown, L. A., and Sattelle, D. B. (2005). Insect GABA receptors: splicing, editing, and targeting by antiparasitics and insecticides. Mol. Pharmacol. 68, 942-951.

Busto, G. U., Cervantes-Sandoval, I., and Davis, R. L. (2010). Olfactory learning in Drosophila. Physiology (Bethesda) 25, 338-346.

Calabrese, E. (2004). Hormesis: from marginalization to mainstream - a case for hormesis as the default dose-response model in risk assessment. Toxicol. Appl. Pharmacol. 197, 125-136.

Calabrese, E., and Baldwin, L. (2003). Toxicology rethinks its central belief - hormesis demands a reappraisal of the way risks are assessed. Nature 421, 691-692.

Casida, J. E. (2009). Pest toxicology: the primary mechanisms of pesticide action. Chem. Res. Toxicol. 22, 609-619.

Christensen, T. A., and Hildebrand, J. G. (2002). Pheromonal and hostodor processing in the insect antennal lobe: how different? Curr. Opin. Neurobiol. 12, 393-399.

Clark, D., and Haynes, K. (1992). Sublethal effects of cypermethrin on chemical communication, courtship, and oviposition in the cabbage-looper (Lepidoptera, Noctuidae). J. Econ. Entomol. 85, 1771-1778.

Cohen, E. (2006). Pesticide-mediated homeostatic modulation in arthropods. Pestic. Biochem. Physiol. 85, 21-27.

Cutler, G. C., Ramanaidu, K., Astatkie, T., and Isman, M. B. (2009). Green peach aphid, Myzus persicae (Hemiptera: Aphididae), reproduction during exposure to sublethal concentrations of imidacloprid and azadirachtin. Pest Manag. Sci. 65, 205-209.

Dallaire, R., Labrecque, A., Marcotte, M., Bauce, E., and Delisle, J. (2004). The sublethal effects of tebufenozide on the precopulatory and copulatory activities of Choristoneura fumiferana and C. rosaceana. Entomol. Exp. Appl. 112, 169-181.

Davies, T. G., Field, L. M., Usherwood, P. N., and Williamson, M. S. (2007). DDT, pyrethrins, pyrethroids and insect sodium channels. IUBMB Life 59, 151-162.

De Belle, J. S., and Kanzaki, R. (1999). "Protocerebral processing," in Insect Olfaction, ed. B. S. Hansson (Berlin: Springer), 243-282.

Decourtye, A., Devillers, J., Aupinel, P., Brun, F., Bagnis, C., Fourrier, J., and Gauthier, M. (2011). Honeybee tracking with microchips: a new methodology to measure the effects of pesticides. Ecotoxicology 20, 429-437.

Deglise, P., Grünewald, B., and Gauthier, M. (2002). The insecticide imidacloprid is a partial antagonist of the nicotinic receptor of honeybee Kenyon cells. Neurosci. Lett. 321, 13-16.

Desneux, N., Decourtye, A., and Delpuech, J.-M. (2007). The sublethal effects of pesticides on beneficial arthropods. Annu. Rev. Entomol. 52, 81-106.

Díaz, M. F., Ramírez, A., and Poveda, K. (2012). Efficiency of different egg parasitoids and increased floral diversity for the biological control of noctuid pests. Biol. Control 60, 182-191.

El Hassani, A. K., Dacher, M., Gauthier, M., and Armengaud, C. (2005). Effects of sublethal doses of fipronil on the behavior of the honeybee (Apis mellifera). Pharmacol. Biochem. Behav. 82, 30-39.

El Hassani, A. K., Giurfa, M., Gauthier, M., and Armengaud, C. (2008). Inhibitory neurotransmission and olfactory memory in honeybees. Neurobiol. Learn. Mem. 90, 589-595.
Faber, T., Joerges, J., and Menzel, R. (1999). Associative learning modifies neural representations of odors in the insect brain. Nat. Neurosci. 2 , 74-78.

Gadenne, C., Dufour, M. C., and Anton, S. (2001). Transient postmating inhibition of behavioural and central nervous responses to sex pheromone in an insect. Proc. R. Soc Lond. B Biol. Sci. 268, 1631-1635.

Gadenne, C., Renou, M., and Sreng, L. (1993). Hormonal control of sex pheromone responsiveness in the male black cutworm, Agrotis ipsilon. Experientia 49, 721-724.

Galizia, C., and Rössler, W. (2010). Parallel olfactory systems in insects: anatomy and function. Annu. Rev. Entomol. 55, 399-420.

Guedes, N. M. P., Tolledo, J., Correa, A. S., and Guedes, R. N. C. (2010). Insecticide-induced hormesis in an insecticide-resistant strain of the maize weevil, Sitophilus zeamais. J. Appl. Entomol. 134, 142-148. Guez, D., Belzunces, L. P., and Maleszka, R. (2003). Effects of imidacloprid metabolites on habituation in honeybees suggest the existence of two subtypes of nicotinic receptors differentially expressed during adult development. Pharmacol. Biochem. Behav. 75, 217-222.

Hardin, M., Benrey, B., Coll, M., Lamp, W., Roderick, G., and Barbosa, P. (1995). Arthropod pest resistance an overview of potential mechanisms. Crop Prot. 14, 3-18.

Haynes, K., and Baker, T. (1985) Sublethal effects of permethrin on the chemical communicationsystem of the pink bollworm moth, Pectinophora gossypiella. Arch. Insect Biochem. Physiol. 2, 283-293.

Haynes, K., Li, W., and Baker, T. (1986). Control of pink-bollworm moth (Lepidoptera, Gelechiidae) with insecticides and pheromones (attracticide) - lethal and sublethal effects. J. Econ. Entomol. 79, 1466-1471.

Haynes, K. F. (1988). Sublethal effects of neurotoxic insecticides on insect behavior. Annu. Rev. Entomol. 33, 149-168.

Heisenberg, M. (2003). Mushroom body memoir: from maps to models. Nat. Rev. Neurosci. 4, 266-275.

Hildebrand, J. G. (1995). Analysis of chemical signals by nervous systems. Proc. Natl. Acad. Sci. U.S.A. 92, 67-74.

Hoelscher, J., and Barrett, B. (2003). Effects of methoxyfenozide-treated surfaces on the attractiveness and responsiveness of adult leafrollers. Entomol. Exp. Appl. 107, 133-140.
Jacquin-Joly, E., and Lucas, P. (2005). Pheromone reception and transduction: mammals and insects illustrate converging mechanisms across phyla. Curr. Top. Neurochem. 4, 75-105.

Kadala, A., Charreton, M., Jakob, I., Le Conte, Y., and Collet, C. (2011). A use-dependent sodium current modification induced by type I pyrethroid insecticides in honeybee antennal olfactory receptor neurons. Neurotoxicology 32, 320-330.

Keil, T. A. (1999). "Morphology and development of the peripheral olfactory organs," in Insect Olfaction, ed. B. S. Hansson (Berlin: Springer), 5-48.

Knight, A. L., and Flexner, L. (2007). Disruption of mating in codling moth (Lepidoptera: Tortricidae) by chlorantranilipole, an anthranilic diamide insecticide. Pest Manag. Sci. 63, 180-189.

Kullik, S. A., Sears, M. K., and Schaafsma, A. W. (2011). Sublethal effects of cry $1 \mathrm{~F}$ Bt corn and clothianidin on black cutworm (Lepidoptera: Noctuidae) larval development. J. Econ. Entomol. 104, 484-493.

Ling, S., Zhang, H., and Zhang, R. (2011). Effect of fenvalerate on the reproduction and fitness costs of the brown planthopper, Nilaparvata lugens and its resistance mechanism. Pest Biochem. Phys. 101, 148-153.

Linn, C., and Roelofs, W. (1984). Sublethal effects of neuroactive compounds on pheromone response thresholds in male oriental fruit moths Arch. Insect Biochem. Physiol. 1, 331-344.

Linn, C. E., and Roelofs, W. L. (1985). Multiple effects of octopamine and chlordimeform on pheromone response thresholds in the cabbage looper moth, Trichoplusia ni. Pestic. Sci. 16, 445-446.

Liu, F., Bao, S. W., Song, Y., Lu, H. Y., and Xu, J. X. (2010). Effects of imidacloprid on the orientation behavior and parasitizing capacity of Anagrus nilaparvatae, an egg parasitoid of Nilaparvata lugens. Biocontrol 55, 473-483.

Lucas, P., and Renou, M. (1992). Electrophysiological study of the effects of deltamethrin, bioresmethrin, and DDT on the activity of pheromone receptor neurons in 2 moth species. Pest. Biochem. Phys. 43, 103-115.

Lürling, M., and Scheffer, M. (2007). Info-disruption: pollution and the transfer of chemical information between organisms. Trends Ecol. Evol. 22, 374-379. 
Menzel, R., and Müller, U. (1996). Learning and memory in honeybees: from behavior to neural substrates. Annu. Rev. Neurosci. 19, 379-404.

Merzendorfer, H., Kim, H. S., Chaudhari, S. S., Kumari, M., Specht, C. A., Butcher, S., Brown, S. J., Robert Manak, J., Beeman, R. W., Kramer, K. J., and Muthukrishnan, S. (2012). Genomic and proteomic studies on the effects of the insect growth regulator diflubenzuron in the model beetle species Tribolium castaneum. Insect Biochem. Mol. Biol. 42, 264-276.

Mommaerts, V., Reynders, S., Boulet, J., Besard, L., Sterk, G., and Smagghe, G. (2010). Risk assessment for side-effects of neonicotinoids against bumblebees with and without impairing foraging behavior. Ecotoxicology 19, 207-215.

Moore, R. (1988). Inhibition of chemical communication between male and female bollworms (Lepidoptera, Noctuidae) by sublethal amounts of permethrin. J. Econ. Entomol. 81, 78-82.

Morse, J. (1998). Agricultural implications of pesticide-induced hormesis of insects and mites. Hum. Exp. Toxicol. 17, 266-269.

Mota-Sanchez, D., Hollingworth, R. M., Grafius, E. J., and Moyer, D. D. (2006). Resistance and crossresistance to neonicotinoid insecticides and spinosad in the Colorado potato beetle, Leptinotarsa decemlineata (Say) (Coleoptera: Chrysomelidae). Pest Manag. Sci. 62, 30-37.

Nauen, R., Ebbinghaus-Kintscher, U., and Schmuck, R. (2001). Toxicity and nicotinic acetylcholine receptor interaction of imidacloprid and its metabolites in Apis mellifera (Hymenoptera: Apidae). Pest Manag. Sci. 57, 577-586.

Oliveira, E. E., Schleicher, S., Buschges, A., Schmidt, J., Kloppenburg, P., and Salgado, V. L. (2011). Desensitization of nicotinic acetylcholine receptors in central nervous system neurons of the stick insect (Carausius morosus) by imidacloprid and sulfoximine insecticides. Insect Biochem. Mol. Biol. 41, 872-880.

Reinke, M. D., and Barrett, B. A. (2007). Sublethal exposure to methoxyfenozide-treated surfaces reduces the attractiveness and responsiveness in adult oriental fruit moth (Lepidoptera: Tortricidae). J. Econ. Entomol. 100, 72-78.

Sakurai, T., Mitsuno, H., Haupt, S. S., Uchino, K., Yokohari, F., Nishioka, T., Kobayashi, I., Sezutsu, H., Tamura, T., and Kanzaki, R. (2011). A single sex pheromone receptor determines chemical response specificity of sexual behavior in the silkmoth Bombyx mori. PLoS Genet. 7, e1002115. doi:10.1371/journal.pgen.1002115

Shi, X., Jiang, L., Wang, H., Qiao, K., Wang, D., and Wang, K. (2011). Toxicities and sublethal effects of seven neonicotinoid insecticides on survival, growth and reproduction of imidacloprid-resistant cotton aphid, Aphis gossypii. Pest Manag. Sci. 67, 1528-1533.

Stengl, M. (2010). Pheromone transduction in moths. Front Cell. Neurosci. 4:133. doi:10.3389/fncel.2010.00133

Tan, J., Galligan, J. J., and Hollingworth, R. M. (2007). Agonist actions of neonicotinoids on nicotinic acetylcholine receptors expressed by cockroach neurons. Neurotoxicology 28 , 829-842.

Wang, G., Huang, X., Wei, H., and Fadamiro, H. Y. (2011). Sublethal effects of larval exposure to indoxacarb on reproductive activities of the diamondback moth, Plutella xylostella (L.) (Lepidoptera: Plutellidae). Pest Biochem. Phys. 101, 227-231.

Wang, S. P., Zhang, S. W., Sato, K., and Srinivasan, M. V. (2005). Maturation of odor representation in the honeybee antennal lobe. J. Insect Physiol. 51, 1244-1254.

Wegerhoff, R., Rossler, W., Higgins, M., Oland, L., and Tolbert, L. (2001). Fenvalerate treatment affects development of olfactory glomeruli in Manduca sexta. J. Comp. Neurol. 430 , 533-541.

Wei, H., and Du, J. (2004). Sublethal effects of larval treatment with deltamethrin on moth sex pheromone communication system of the Asian corn borer, Ostrinia furnacalis. Pest Biochem. Phys. 80, 12-20.

Wijayaratne, L. K., Fields, P. G., and Arthur, F. H. (2012). Effect of methoprene on the progeny production of Tribolium castaneum (Coleoptera: Tenebrionidae). Pest Manag. Sci. 68, 217-224.

Wüstenberg, D. G., and Grünewald, B. (2004). Pharmacology of the neuronal nicotinic acetylcholine receptor of cultured Kenyon cells of the honeybee, Apis mellifera. J. Comp. Physiol. A 190, 807-821.

Yang, E. C., Chuang, Y. C., Chen, Y. L., and Chang, L. H. (2008). Abnormal foraging behavior induced by sublethal dosage of imidacloprid in the honey bee (Hymenoptera: Apidae). J. Econ. Entomol. 101, 1743-1748.

Zhou, H., Du, J., and Huang, Y. (2005). Effects of sublethal doses of malathion on responses to sex pheromones by male Asian corn borer moths, Ostrinia furnacalis (guenée). J. Chem. Ecol. 31, 1645-1656.

Conflict of Interest Statement: The authors declare that the research was conducted in the absence of any commercial or financial relationships that could be construed as a potential conflict of interest.

Received: 01 February 2012; paper pending published: 22 February 2012; accepted: 29 February 2012; published online: 19 March 2012.

Citation: Tricoire-Leignel H, Thany SH, Gadenne $C$ and Anton $S$ (2012) Pest insect olfaction in an insecticide-contaminated environment: info-disruption or hormesis effect. Front. Physio. 3:58. doi: 10.3389/fphys.2012.00058

This article was submitted to Frontiers in Invertebrate Physiology, a specialty of Frontiers in Physiology. Copyright (C) 2012 Tricoire-Leignel, Thany, Gadenne and Anton. This is an open-access article distributed under the terms of the Creative Commons Attribution Non Commercial License, which permits non-commercial use, distribution, and reproduction in other forums, provided the original authors and source are credited. 